\title{
PREVALENCE OF GASTRO-INTESTINAL PARASITES IN CAPTIVE BIRDS OF GUJARAT ZOOS
}

\author{
P.V. Patel ${ }^{1}$, A.I. Patel ${ }^{2}$, R.K. Sahu ${ }^{3}$ and Raju Vyas ${ }^{4}$ \\ ${ }^{1}$ Assistant Professor, ${ }^{2}$ Professor and Head, College of Veterinary Science and Animal Husbandry, Department of Parasitology, \\ Gujarat Agricultural University, Anand, Gujarat 388001, India. \\ ${ }^{3}$ Zoo Superintendent, Kamala Nehru Zoological Park, Ahmedabad, Gujarat, India. \\ ${ }^{4}$ Sayyajibaug Zoo, Vadodara, Gujarat, India.
}

\begin{abstract}
A total of 106 group faecal samples of different wild birds from Kamal Nehru Zoo, Ahmedabad and Sayyajibaug Zoo, Vadodara, were examined. Out of this $51(48.11 \%)$ were found positive for parasitic infection. Eggs of Ascaris and Capillaria species were observed in $22(20.75 \%)$ and $14(13.2 \%)$ group faecal samples respectively, while the oocyst of Coccidia (Eimeria species) were observed in 19 (17.92\%) group faecal samples. Ascardia galli and Cotugnia digonopora were recovered during postmortem of three hariyal pigeon, while only Ascaridia galli was observed in a postmortem of parrot, peacock and cockatiel.
\end{abstract}

\section{Introduction}

Parasitic infections cause considerable losses to wildlife in this country. In zoological parks, the birds are under constant stress and are prone to parasitic infections. A study was therefore conducted to note and place on record the incidence of gastrointestinal parasitic infections in wild birds of Sayyajibaug Zoo, Baroda and Kamala Nehru National Park Zoo, Ahmedabad of Gujarat State.

\section{Material and Methods}

Fresh group faecal samples of birds kept in different cages/ enclosures were collected in plastic bags and were processed by sedimentation technique in the laboratory. A part of each sample was also mixed with 2.5 per cent potassium dichromate solution in petridishes and kept at room temperature for sporulation of coccidian oocysts. Gross helminths passed in faeces and those collected at postmortem were identified after staining them with borax carmine in case of trematodes andf cestodes. Nematodes were studied after clearing them in lactophenol.

Received on 16 August 1999
Accepted on 3 March 2000

\section{Results and Discussion}

The results of the faecal sample examination are presented in Table 1. A total of 106 group faecal samples of different wild captive birds were examined, out of which 51 (48.11\%) were found positive for parasitic infection.

Eggs of Ascaris and Capillaria species were observed in 22 $(20.75 \%)$ and $14(13.2 \%)$ group faecal samples respectively, while the oocytsts of coccidia were observed in 19 (17.92\%) group faecal samples. The egg size of Ascaris sp. ranged from $64-78 \times 32-45 \mu \mathrm{m}$, while that of Capillaria sp. were 44-60 x 22-24 $\mu \mathrm{m}$ and oocysts of Eimeria sp. were 15-20 x 10-16 $\mu \mathrm{m}$. Such findings were also recorded by Pande et al. (1970) in wild birds and by Soulsby (1982). Ascaridia galli were observed in a postmortem of parrot, peacock and cockatiel.

The percentage of coccidial (Eimeria spp.) infection was low when compared to helminthic infection and the commonest infection was of Ascaris spp. followed by coccidia (Eimeria spp.) and Capillaria spp. Oocysts of Eimeria spp. were found in most birds either as pure infection (peacock, parrot, pheasant, love bird, ducks, kaka kowa, koel) or as a mixed infection (pigeon and lory bird) with other helminths. Such findings were also recorded by Patnaik and Acharjyo (1970), Tripathy et al. (1971), Chauhan et al. (1973), Khan (1979), Muraleedharan et al. (1990) and Reddy et al. (1992).

\section{References}

Chauhan, P.P.S., B.B. Bharia, G.S. Arora, R.D. Agarwal and S.S. Ahluwalia (1973). A prliminary survey of parasitic infection among mammals and birds at Lucknow and Delhi Zoos. Indian J. Anim. Sci. 43: $163-68$.

Khan, A.M. (1979). Incidence of different parasites in wild life of Nehru Zoological Park, Hyderabad. In: Proceedings of Summer Institute of Pathology of Wildlife (ICAR-UAS), Veterinary College, Bangalore held on 16-29 May, 1979.

Muraleedharan, K., V. Iswaraiah, S.K. Ziauddin and K. Srinivasan (1990). A survey of gastrointestinal parasites of mammals of zoological gardens at Mysore. Mysore J. Agri. Sci. 24: 250- 
Table 1. Prevalence of parasitic infection in captive wild birds of Gujarat zoos

\begin{tabular}{|c|c|c|c|c|}
\hline Species of birds & $\begin{array}{l}\text { Number of } \\
\text { group sample } \\
\text { examined }\end{array}$ & $\begin{array}{l}\text { No. } \\
\text { positive }\end{array}$ & $\begin{array}{l}\text { Percent } \\
\text { positive }\end{array}$ & Identification of eggs/oocyst \\
\hline $\begin{array}{l}\text { 1. Fowl } \\
\text { (Gallus spp., Peafowl, Pava Spp., Polishfowl, Cochinfowl) }\end{array}$ & 14 & 9 & 64.28 & $\begin{array}{l}\text { Eimeria sp. (4), Ascaris sp. (2) } \\
\text { Capillaria sp. (3) }\end{array}$ \\
\hline 2. Parrot (Psittacus spp. - Gray parrot) & 6 & 2 & 33.33 & Eimeria sp. (1), Capillaria sp. (1) \\
\hline $\begin{array}{l}\text { 3. Pigeon } \\
\text { (Columba spp. - Homer Pigeon, Hariyal Pigeon, Crown Pigeon, Red Ja } \\
\text { Pigeon, White Silky Pigeon, Green Pigeon, Blue Pigeon, Puter Pigeon) }\end{array}$ & $\begin{array}{l}28 \\
\text { acoban }\end{array}$ & 15 & 53.57 & $\begin{array}{l}\text { Eimeria sp. (4) } \\
\text { Eimeria sp. (1), Ascaris sp. (1), } \\
\text { Ascaris sp. (5), Capillaria sp. (5) }\end{array}$ \\
\hline $\begin{array}{l}\text { 4. Pheasant (Chrysolophus spp. - Lady Amherst } \\
\text { Pheasant, Golden Pheasant, Lophura spp.- Silver Pheasant) }\end{array}$ & 8 & 3 & 37.50 & Eimeria sp. (2), Ascaris sp. (1) \\
\hline $\begin{array}{l}\text { 5. Lory (Psittaciformes spp.) } \\
\text { (Red Molical Lory, Rainbow Lory, Black-caped Lory) }\end{array}$ & 6 & 2 & 33.33 & $\begin{array}{l}\text { Eimeria sp. (1), Ascaris sp. (1), } \\
\text { Ascaris sp. (1) }\end{array}$ \\
\hline 6. Love bird (Agapornis spp.) & 3 & 2 & 66.66 & Eimeria sp. (1), Ascaris sp. (1) \\
\hline 7. Duck (Tadona spp.) & 3 & 2 & 66.66 & Eimeria sp. (1), Ascaris sp. (1) \\
\hline 8. White Cockatoo (Cacatoe spp.) & 2 & 1 & 50.00 & Capillaria sp. (1) \\
\hline 9. Rossela (Platycerus spp.) & 2 & - & - & - \\
\hline 10. Cassowary (Casuarius spp.) & 2 & 1 & 50.00 & Ascaris sp. (1) \\
\hline 11. Mekad (Ara movacana), (Red and Green Mekab, Eligresh Mekab) & 6 & 3 & 50.00 & Eimeria sp. (1), Capillaria sp. (1) \\
\hline 12. Kaka kowa (Cacatua spp.) & 3 & 2 & 66.66 & Eimeria sp. (2) \\
\hline 13. Emu (Dromiceins spp.) & 4 & - & - & - \\
\hline 14. Amazon Parrot (Amazona spp.) & 2 & 1 & 50.00 & Ascaris sp. (1) \\
\hline 15. White Stork (Cinconia spp.) & 2 & 1 & 50.00 & Ascaris sp. (1) \\
\hline 16. Spoon bill (Platalea spp.) & 2 & 1 & 50.00 & Ascaris sp. (1) \\
\hline 17. Gidia Conur (Arotinga spp.) & 3 & 1 & 33.33 & Ascaris sp. (1) \\
\hline 18. Parakeet (Psittacula spp. - Rose-ringed, Blossom-headed) & 4 & 2 & 50.00 & Capillaria sp. (2) \\
\hline 19. White Java Sparrow (Padda spp.) & 4 & 2 & 50.00 & Ascaris sp. (1), Capillaria sp. (1) \\
\hline 20. Koel (Endynoms spp.) & 2 & 1 & 50.00 & Eimeria sp. (1) \\
\hline Total & 106 & 51 & 48.11 & \\
\hline
\end{tabular}

Numbers in parentheses indicate the number of positive groups of sample.

56.

Pande, B.P., B.B. Bhatia, P.P.S. Chauhan and R.K. Garg (1970). Species composition of coccidia of some of the mammals and birds at the Zoological Gardens, Lucknow. Indian J. Anim. Sci. 40: 154-163. Patnaik, M.M. and L.N. Acharyjo (1970). Notes on the helminth parasites of vertebrates in Baranga Zoo (Orissa). Indian Vet. J. 47: 723-730.

Reddy, N.R., Jaya Gopala, M.S. Jagannath, P.E. D'souza, A. Rahman, and Basavarajappa (1992). Prevalence of gastro- intestional parasites in wild mammals and captive birds at Bannerghatta National Park, Bangalore. Indian J. Anim. Sci. 62(11): 1046-1048.

Soulsby E.J.L. (1982). Helminths, Arthropods and Protozoa of domesticated animals. E.L.B.S. 7th edition.

Tripathi, S.B., L.N. Acharya, A.T. Rao, K.C. Patnaik and S.K. Misra (1971). Survey of intestional parasitic infection in animals and birds. Indian J. Anim. Hlth. 10: 107-110. 